\title{
A percepção de docentes acerca da contribuição da filosofia para a formação do contador no Brasil sob a vigência das Financial Reporting Standards (IFRS)
}

The perception of teachers about the contribution of philosophy to accountant education in Brazil under the Financial Reporting Standards (IFRS)

La percepción de docentes acerca de la contribución de la filosofía para la formación del contador en Brasil bajo la vigencia de las Financial Reporting Standards (IFRS)

\section{Thiago Cunha de Oliveira}

Doutorando no Programa de Pós-Graduação em Administração da Universidade do Grande Rio - PPGA (UNIGRANRIO)

Endereço: Rua Professor José de Souza Herdy, 1160, bloco C, Jardim 25 de Agosto CEP: 25071-202 - Duque de Caxias/RJ - Brasil

E-mail: thiaguhc@gmail.com

Telefone: (21) 2672-7776

\section{Claudia Ferreira da Cruz}

Doutora em Controladoria e Contabilidade pela FEA (USP)

Professora do Programa de Pós-Graduação em Ciências Contábeis da Universidade Federal do Rio de Janeiro - PPGCC (UFRJ)

Endereço: Av. Pasteur, 250, sala 250, Urca

CEP: 22.290-902 - Rio de Janeiro/RJ - Brasil

E-mail: claudiacruz@facc.ufrj.br

Telefone: (21) 3938-5117

\section{André Luiz Bufoni}

Doutor em Planejamento Ambiental pela COPPE (UFRJ)

Professor do Programa de Pós-Graduação em Ciências Contábeis da Universidade Federal do Rio de Janeiro - PPGCC (UFRJ)

Endereço: Av. Pasteur, 250, sala 250, Urca

CEP: 22.290-902 - Rio de Janeiro/RJ - Brasil

E-mail: bufoni@facc.ufrj.br

Telefone: (21) 3938-5117

Artigo recebido em 24/02/2018. Revisado por pares em 25/03/2019. Reformulado em 15/04/2020. Recomendado para publicação em 15/04/2020 por Carlos Eduardo Facin Lavarda (Editor-Chefe). Publicado em 24/04/2020. 


\title{
Resumo
}

A adoção às normas internacionais de contabilidade requer a capacidade de julgamento por parte dos discentes de Ciências Contábeis a fim de realizarem tomadas de decisão que envolvam subjetivismo profissional, advindo de uma contabilidade baseada em princípios. Assim, este estudo exploratório tem por objetivo investigar a relevância da Filosofia para a formação do contador no Brasil sob a vigência das IFRS. Foram realizadas dez entrevistas semiestruturadas com docentes que ministram disciplinas que abordam as normas contábeis nos cursos de Ciências Contábeis em universidades públicas no estado do Rio de Janeiro, sendo os dados analisados segundo a metodologia de análise de conteúdo e com auxílio do software Nvivo11. Verificou-se que a Filosofia é relevante e agrega positivamente a formação do futuro profissional contábil, visto que auxilia os discentes no que tange lidar com o subjetivismo advindo da adoção às normas internacionais de contabilidade, além de estimular a criticidade dos mesmos.

Palavras-chave: Filosofia; Educação Contábil; IFRS; Interdisciplinaridade

\begin{abstract}
The adoption of international accounting standards requires the ability to judge by accounting students in order to make decisions that involve professional subjectivism, derived from principlesbased accounting. Thus, this exploratory study aims to investigate the relevance of Philosophy to the formation of the accountant in Brazil under the IFRS. Ten semi-structured interviews were conducted with professors who teach subjects that deal with accounting standards in accounting courses at public universities in the state of Rio de Janeiro being the data analysed according to the content analysis methodology and with the software Nvivoll. It was verified that Philosophy is relevant and positively adds the formation of the future accounting professional, since it assists students in dealing with subjectivism arising from the adoption of international accounting standards, as well as stimulating their criticality.
\end{abstract}

Keywords: Philosophy; Accounting Education; IFRS; Interdisciplinarity

\section{Resumen}

La adopción a las normas internacionales de contabilidad requiere la capacidad de juicio de los discentes de Contabilidad a fin de realizaren tomas de decisión que involucran subjetivismo profesional, proveniente de una contabilidad basada en principios. Este estudio exploratorio tiene por objetivo investigar la relevancia de la Filosofía para la formación del contador en Brasil bajo la vigencia de las IFRS. Se realizaron diez entrevistas semiestructuradas a docentes que ministran disciplinas que abordan las normas contables en cursos de Contabilidad en universidades públicas en el estado de Río de Janeiro, siendo los datos analizados según la metodología de análisis de contenido y con el software Nvivo11. Se verificó que la Filosofía es relevante y agrega positivamente la formación del futuro contador, auxiliando los discentes a lidiar con el subjetivismo proveniente de la adopción a las normas internacionales de contabilidad, además de estimular la criticidad de los mismos.

Palabras Clave: Filosofía; Educación Contable; IFRS; Interdisciplinariedad

\section{Introdução}

A Filosofia pode ser entendida como um estudo que se preocupa com as ideias, com o pensamento, os fatos e princípios da existência, com os valores, com a natureza das coisas e as relações que elas estabelecem entre si, também, com a conduta e o comportamento humano, para que não haja aceitação de tudo de maneira pronta e evidente, sem antes se proceder a uma adequada investigação e compreensão dos acontecimentos e da realidade (CHAUI, 2001).

Para a Contabilidade, a Filosofia cumpre o papel de promover um estudo superior, 
profundo e de amplo aspecto, que se caracteriza pela intenção de ampliar incessantemente a compreensão da realidade, no sentido de aprendê-la na sua totalidade, conforme menciona Hoog (2013). Afastar ou ignorar o estudo da Filosofia pode ocasionar a hipertrofia do conhecimento teórico, em detrimento da prática contábil, o que impediria que o intérprete da contabilidade estabelecesse relações entre causas e efeitos patrimoniais, bem como fizesse suas análises e avaliações (HOOG, 2013). Ainda, de acordo com o mesmo autor, a Filosofia facilita o entendimento e a interpretação dos fenômenos patrimoniais ocorridos em âmbito contábil, proceder que não se restringe apenas ao campo teórico, devendo ser utilizada pelo contador em toda sua atividade profissional.

Com a adoção das International Financial Reporting Standards (IFRS) no Brasil, em vigência desde 2010 e caracterizadas por um sistema contábil baseado em princípios, os contadores passaram a ser exigidos com relação à avaliação da melhor forma de contabilização de um evento patrimonial, requerendo a utilização em maior escala de juízo de valor para com transações de natureza subjetiva e tomadas de decisão (PAULO; CARVALHO; GIRÃO, 2014).

A contabilidade como ciência social deve acompanhar as mudanças da sociedade na qual está inserida e, assim, "refletir as diferentes condições sócio-econômico-político-legais" (SZÜSTER; SZÜSTER; SZÜSTER, 2005). Acompanhando tais mudanças, o Conselho Federal de Contabilidade (CFC), propôs que fosse incluída nas grades curriculares de cursos superiores em Ciências Contábeis a matéria Filosofia da Ciência, com objetivo de desenvolver o raciocínio lógico a partir da consciência histórico-filosófica (CFC, 2009). Consoante estudo realizado por Araújo (2015), apenas 16\% das Instituições Federais de Ensino Superior que oferecem curso de graduação em Ciências Contábeis de forma presencial disponibilizaram a disciplina "Filosofia da Ciência", sendo esta a quinta menos oferecida dentre as trinta e nove recomendadas pelo CFC, excetuando-se as optativas.

Diante do exposto, o objetivo do presente estudo é investigar a percepção de docentes do curso de Ciências Contábeis com relação à relevância da Filosofia para a contabilidade, mais especificamente, para a tomada de decisões por profissionais da área; tendo o mesmo a seguinte questão de pesquisa: de que forma se configura a relevância da Filosofia para a formação do contador, sob a percepção de docentes, em relação à tomada de decisão sob a vigência das IFRS? Tal tomada de decisão, segundo Iudícibus et al. (2010), constitui um dos principais objetivos da Contabilidade, bem como é algo inerente ao papel do Contador.

A fim de cumprir o objetivo proposto, foram realizadas entrevistas presenciais semiestruturadas com docentes de universidades públicas do estado do Rio de Janeiro - ao menos dois de cada - que possuem o curso de Ciências Contábeis. As respostas obtidas foram analisadas e comparadas com auxílio do software QSR NVIVO 11, fornecendo material para que o estudo alcançasse o seu objetivo de compreender a importância da temática para a prática contábil.

Com relação à relevância desta pesquisa, entende-se que poderá agregar em ao menos três aspectos, quais sejam: teórico, dado que soma-se, consoante Martins (2012) e Silva (2014), ao pequeno quantitativo de estudos nos quais os autores tenham buscado relacionar pressupostos filosóficos à contabilidade - os quais são relevantes, também, por irem de encontro aos paradigmas funcionalistas, que são majoritários no âmbito da pesquisa contábil, e, assim, acrescentando à uma maior pluralidade de óticas nas pesquisas contábeis; prático, visto que busca-se analisar a pertinência da Filosofia no que diz respeito a possibilitar uma maior compreensão da prática contábil, especialmente a relacionada ao subjetivismo contábil, o qual requer um novo perfil de contador (ESPEJO et al., 2010a; FUJI; SLOMSKI, 2003); e social, pois, o pensamento filosófico, ademais da prática profissional, influencia, nos aspectos críticos, nas subjetividades dos sujeitos enquanto seres sociais inseridos nas mais diversas estruturas, possibilitando, dentre outros aspectos, reflexões mais profundas sobre o meio social (CABRAL; SIQUEIRA; SIQUEIRABATISTA, 2011; LAFFIN, 2004; MALUSÁ et al., 2015).

O presente artigo apresenta, além da introdução, a revisão de literatura, abordando: a 
adoção do International Financial Reporting Standards no Brasil e a contabilidade baseada em princípios, as relações entre a Filosofia e a contabilidade e estudos correlatos; em seguida, é apresentada a metodologia para a realização da pesquisa e, por fim, a análise de dados, as considerações finais e as referências.

\section{Fundamentação Teórica}

\subsection{A adoção do International Financial Reporting Standards no Brasil e a contabilidade baseada em princípios}

O processo de convergência às normas contábeis internacionais no Brasil foi marcado, em suma, por dois acontecimentos: a criação do Comitê de Pronunciamentos Contábeis (CPC) pela Resolução $\mathrm{n}^{\circ}$ 1.055/2005 e a promulgação da Lei $\mathrm{n}^{\circ}$ 11.638/2007 (MACEDO et al., 2013). Contudo, cabe ressaltar alguns acontecimentos prévios igualmente relevantes, como o anteprojeto de reformulação da Lei $n^{\circ}$ 6.404/1976, denominado Projeto de Lei $n^{\circ} 3.741$, que foi encaminhado pela Comissão de Valores Mobiliários (CVM) ao Ministério da Fazenda, com objetivo de criar condições para a harmonização da lei com as práticas contábeis internacionais, tendo sido este projeto a dar origem à Lei no 11.638/2007 (LEMES; CARVALHO, 2009).

O CPC tem a finalidade de estudar, preparar e divulgar procedimentos contábeis por meio de pronunciamentos técnicos que devem ser obrigatoriamente submetidos à audiência pública e análise das entidades reguladoras competentes, visando, assim, a convergência da contabilidade brasileira aos padrões internacionais. Tais análises são necessárias, uma vez que o Comitê não possui competência legislativa, isto porque a Constituição Federal veda que órgãos governamentais deleguem funções a outras entidades (IUDÍCIBUS et al., 2010). Por tal razão, os Pronunciamentos Contábeis, ainda que aprovados pelo CPC, devem ser também emitidos por órgãos com competência normativa, a fim de que sua aplicação seja obrigatória em território nacional (OLIVEIRA et al., 2013).

A Lei $n^{0} 11.638 / 2007$, foi responsável por modificar, dentre outras coisas, diversos dispositivos que regulavam as demonstrações contábeis na Lei das Sociedades por Ações (COSTA; ALMEIDA; SILVA, 2013), destacando-se a inclusão do § $5^{\circ}$ no art. 177, segundo o qual as normas expedidas pela CVM devem ser elaboradas em consonância com as normas internacionais de contabilidade (BRAGA, 2011).

A adoção das IFRS, normas emitidas pelo International Accounting Standards Board (IASB), resultou no aumento da influência do padrão contábil europeu nas normas brasileiras, as quais, desde o início da vigência da Lei $\mathrm{n}^{\circ}$ 6.404/1976, estiveram alinhadas às práticas contábeis norte-americanas (NIYAMA, 2010). As regras editadas pelo Financial Accounting Standards Board (FASB), geralmente são baseadas em regras, ainda que sejam emitidas de forma conceitual, enquanto as originárias do IASB são baseadas em princípios, visto que deixam mais espaço para julgamentos profissionais (MOTA et al., 2016).

Portanto, consoante Geron (2008), a mudança mais significativa advinda da nova lei é a filosófica contábil, visto que o profissional necessitará de uma maior capacidade de julgamento para avaliar conceitos como a primazia da essência econômica sobre a forma, a primazia da análise dos riscos e benefícios sobre a propriedade jurídica e a adoção de normas orientadas em princípios e julgamentos. Visão semelhante é compartilhada por Espejo et al. (2010), ao ressaltarem que, com a adoção das Normas Internacionais de Contabilidade, o contador não deverá ser meramente um cumpridor de regras, mas um profissional com raciocínio crítico-analítico.

\subsection{As Relações entre a Filosofia e a Contabilidade}

Uma maior utilização de conhecimentos advindos de outras ciências, como a Psicologia, 
como suporte às mudanças, a Sociologia, proporcionando melhor entendimento das relações sociais, a Antropologia, visando conhecer a diversidade cultural, e a Filosofia, auxiliando o contínuo repensar dos princípios que norteiam a área, é relevante para a formação do profissional da contabilidade, bem como para o atual momento da área, no qual se discute o aprofundamento das interações contábeis em níveis internacionais (CABRAL; SIQUEIRA; SIQUEIRA-BATISTA, 2011).

O CFC, em sua Proposta Nacional de Conteúdo para o Curso de Graduação em Ciências Contábeis (2009), recomenda que os referidos cursos incluam em suas grades a disciplina Filosofia da Ciência, com objetivo de desenvolver o raciocínio lógico a partir da consciência históricofilosófica; contudo, de acordo com Araújo (2015), tal disciplina não consta na maioria dos cursos oferecidos por Universidades Federais.

A Filosofia, por sua vez, consiste em um saber desprovido de um conceito fechado, possuindo uma variedade de significações. Essas, porém, guardam características constantes que auxiliam no entendimento geral desta área do conhecimento (ABBAGNANO, 1963). Nos últimos 25 séculos de sua existência, a Filosofia desenvolveu importantes campos de investigação, apontados pela filósofa Marilena Chauí (2001, p. 54 e 55), quais sejam: ontologia; epistemologia; lógica; Teoria do Conhecimento; ética; Filosofia Política; Filosofia da História; Filosofia da arte ou estética; Filosofia da Linguagem e História da Filosofia.

Dessas grandes áreas é possível, por meio de análises bibliográficas investigativas, extrair elementos que se relacionam com à pesquisa contábil, quais sejam: (a) conhecimento e ciências; (b) religião; (c) razão e lógica; (d) linguagem; (e) artes; (f) ética e política; (g) verdade e justiça; e (h) cultura, valores e comportamento. O quadro 01, adaptado de Silva (2014), demonstra a conceitualização de pressupostos filosóficos e sua utilização em pesquisas acadêmicas no âmbito contábil.

Quadro 1 - Pressupostos filosóficos e suas aplicações à contabilidade

\begin{tabular}{|c|c|c|}
\hline Pressupostos & Entendimento Filosófico & Aplicação na Ciência Contábil \\
\hline $\begin{array}{l}\text { Conhecimento } \\
\text { Ciências }\end{array}$ & $\begin{array}{l}\text { Ciências, no plural, diz respeito às diversas } \\
\text { formas de realização do ideal de } \\
\text { conhecimento, de acordo com os diferentes } \\
\text { fatos investigados e com os vários métodos } \\
\text { e técnicas empregados (CHAUÍ, 2001). }\end{array}$ & $\begin{array}{l}\text { A Contabilidade é uma ciência social que } \\
\text { tem por objeto o patrimônio, e estuda os } \\
\text { efeitos dos atos patrimoniais (OLIVEIRA } \\
\text { et al., 2003). }\end{array}$ \\
\hline Religião & $\begin{array}{l}\text { A religião implica no sentimento de fé. } \\
\text { Não se dirige ao intelecto, mas sim ao } \\
\text { coração dos homens, que através dos ritos } \\
\text { estreitam as relações entre o terreno e o } \\
\text { divino (CHAUÍ, 2001). }\end{array}$ & $\begin{array}{l}\text { Distintos movimentos religiosos, } \\
\text { econômicos, e políticos da história mundial } \\
\text { implicaram em aperfeiçoamento de práticas } \\
\text { contábeis, atendendo exigências ligadas aos } \\
\text { seus interesses (OLIVEIRA et al., 2003). }\end{array}$ \\
\hline Razão e Lógica & $\begin{array}{l}\text { A lógica apresenta formas de pensamento } \\
\text { e raciocínio amparados na razão, e a } \\
\text { atividade racional se apropria de } \\
\text { raciocínios que mostram uma composição } \\
\text { lógica da realidade (CHAUÍ, 2001). }\end{array}$ & $\begin{array}{l}\text { Corresponde à adoção do conhecimento } \\
\text { sistemático e racional para argumentação } \\
\text { de seus princípios, através da teoria como } \\
\text { Raciocínio e da teoria como Decreto } \\
\text { (SILVA, 2014). }\end{array}$ \\
\hline Linguagem & $\begin{array}{l}\text { É um sistema de signos ou sinais usados } \\
\text { para indicar coisas, para a comunicação e } \\
\text { para expressão de ideias, valores e } \\
\text { sentimentos (CHAUÍ, 2001). }\end{array}$ & $\begin{array}{l}\text { A Contabilidade é uma linguagem, pois } \\
\text { possui um conjunto organizado de signos e } \\
\text { um sistema de comunicação próprio } \\
\text { (WEFFORT, 2005). }\end{array}$ \\
\hline Artes & $\begin{array}{l}\text { Ação individual espontânea, que revela a } \\
\text { criação do artista, através de sua } \\
\text { sensibilidade e inspiração (CHAUÍ, 2001). }\end{array}$ & $\begin{array}{l}\text { O homem primitivo evidenciou, em } \\
\text { pinturas rupestres, a riqueza patrimonial } \\
\text { que detinha, a fim de gerenciá-la. As } \\
\text { histórias da arte e da contabilidade, } \\
\text { portanto, possuem pontos em comum (SÁ, } \\
\text { 2006). }\end{array}$ \\
\hline
\end{tabular}


A percepção de docentes acerca da contribuição da filosofia para a formação do contador no Brasil sob a vigência das Financial Reporting Standards (IFRS)

\begin{tabular}{|l|l|l|}
\hline \multicolumn{1}{|c|}{ Pressupostos } & \multicolumn{1}{|c|}{ Entendimento Filosófico } & \multicolumn{1}{c|}{ Aplicação na Ciência Contábil } \\
\hline Ética e Política & $\begin{array}{l}\text { A conduta ética pressupõe um sujeito com } \\
\text { consciência moral, capaz de julgar atos e } \\
\text { condutas de acordo com os valores morais } \\
\text { (CHAUÍ, 2001). }\end{array}$ & $\begin{array}{l}\text { O profissional contábil deve ter vocação } \\
\text { para a verdade para cumprir o dever ético } \\
\text { (SÁ, 2012). }\end{array}$ \\
\hline Verdade e Justiça & $\begin{array}{l}\text { Tem por intuito encontrar explicações para a } \\
\text { realidade, conduzindo ao que bom e justo } \\
\text { (CHAUÍ, 2001). }\end{array}$ & $\begin{array}{l}\text { Predominância da essência sobre a forma } \\
\text { nas demonstrações contábeis } \\
\text { (WEFFORT, 2005). }\end{array}$ \\
\hline $\begin{array}{l}\text { Cultura, Valores e } \\
\text { Comportamento }\end{array}$ & $\begin{array}{l}\text { A cultura mostra a formação social, o } \\
\text { conjunto de práticas socialmente admitidas e } \\
\text { as instituições estabelecidas, suas leis, suas } \\
\text { crenças e seus valores (CHAUÍ, 2001). }\end{array}$ & $\begin{array}{l}\text { No âmbito organizacional, aspectos } \\
\text { culturais têm promovido investigações } \\
\text { nas quais o comportamento e a prática de } \\
\text { gestão têm sido considerados relevantes } \\
\text { para a vantagem competitiva entre } \\
\text { empresas (LACERDA, 2011). }\end{array}$ \\
\hline
\end{tabular}

Fonte: Adaptado de Silva (2014).

Dessa forma, como explicitado no quadro 1, elaborado com base em pesquisas tanto do âmbito da Filosofia quanto da Ciência Contábil, demonstrou-se, juntamente ao parágrafos contidos na presente subseção, que algumas das conjecturas estudadas naquela área também estão presentes na seara contábil, o que corrobora para com o entendimento de que tais campos do conhecimento, embora possuam objetos de análise distintos, compartilham saberes.

\subsection{Estudos Correlatos}

Há autores que se dedicaram ao estudo da tomada de decisão no âmbito contábil sob influência das normas internacionais de contabilidade, como Espejo et al. (2010a) e Fuji e Slomski (2003), tendo concluído que, a fim de acompanhar a internacionalização da normatização contábil, necessita-se repensar conceitos e práticas até então inerentes à prática contábil. Tal reflexão visa o fortalecimento de um processo que busque a formação de um novo profissional que seja capaz de lidar com o subjetivismo que caracteriza diversas normas contábeis. Estudos como o de Espejo et al. (2010b), Bemfica et al. (2016) e Fonteles, Oliveira e Almeida (2011) indicam que ainda há dificuldades no processo de capacitação do corpo docente e preparo de discentes no que se refere às normas contábeis, embora sejam notadas melhoras.

Outras pesquisas ressaltam a necessidade do desenvolvimento do raciocínio crítico - o qual auxilia no processo de tomada de decisão - no profissional contábil, como as realizadas por Smith (2003), Cornacchione Jr; Duncan e Johson (2007), e Springer e Borthick (2007). Em tais estudos, os autores, em geral, concluíram que deve haver um aprimoramento em métodos que visam o desenvolvimento do raciocínio crítico nos discentes de contabilidade, pois tal prática auxilia os alunos a terem maiores chances de sucesso profissional.

Acerca da importância da interdisciplinaridade no curso de graduação em Ciências Contábeis, estudos como os realizados por Laffin (2004), Padoan e Clemente (2006) e Peleias et al. (2011), ressaltaram a relevância do tema para os atores da prática docente. Acerca da existência da interdisciplinaridade no curso de Ciências Contábeis, pesquisas como as realizadas por Passos (2004) e Cabral; Siqueira e Batista (2011) buscaram avaliar o nível de interdisciplinaridade existente no referido curso. Os resultados obtidos em ambas as pesquisas indicam que há maior necessidade de discussão e efetivação do tema, visto que poucas características interdisciplinares foram observadas no decorrer dos estudos referidos.

Ainda sobre a interdisciplinaridade, os autores Murcia et al. (2015) compararam as ementas dos cursos de Ciências Contábeis oferecidos pelas universidades estaduais brasileiras com os principais programas contábeis oferecidos nos Estados Unidos da América e Reino Unido. Concluiu-se que os currículos oferecidos no Brasil são mais rígidos e tecnicistas que aqueles disponibilizados nos Estados estrangeiros mencionados, possuindo baixa flexibilidade para os 
discentes no que se refere a possibilidade de cursar disciplinas de outras áreas.

Quanto à aplicação da Filosofia às Ciências Sociais Aplicadas, pesquisas como as de Vieira e Castanho (2009) e Bazanini; Pereira e Bazanini (2009), analisaram a relevância da mesma no âmbito da formação do administrador de empresas, constatando que há uma carência da aplicação de conceitos filosóficos na área, além de ressaltaram que tais conceitos auxiliam na formação de administradores com pensamento emancipatório.

No que concerne à relevância da Filosofia especificamente para a Ciência Contábil, produções científicas realizadas por autores como Trombetta e Trombetta (2015) e Silva (2014) analisaram a contribuição dos estudos filosóficos na compreensão de conceitos do âmbito contábil, tendo concluído que a apropriação de concepções filosóficas auxilia na compreensão de conceitos de maior complexidade, assim como na leitura de cenários globais onde o modelo contábil se desenvolve.

No que toca o ensino do pressuposto filosófico mais evidente ao âmbito contábil, a ética, pesquisas, como a elaborada por Martinov-Bennie e Mladenovic (2015), ressaltam a importância do ensino de ética para discentes, mostrando que tal prática, em nível de graduação, impacta de forma positiva o comportamento dos mesmos. Diehl, Freitas e Macagnan (2011), Nascimento et al. (2011) e Magro, Silva e Zonatto (2018), sinalizam que alunos de graduação em Ciências Contábeis têm julgamento moral condizente com o esperado pelo futuro profissional, porém não entendem o conceito de ética, assim como desconhecem o código de ética da profissão.

Embora não tenham sido encontrados estudos nos quais os autores analisem a relevância da Filosofia para a formação do profissional de contabilidade, tampouco a importância da mesma à prática contábil sob a vigência das normas internacionais, a presente pesquisa está relacionada à lacuna apresentada por Martins (2012) e Silva (2014), acerca das relações existentes entre preceitos filosóficos e a seara contábil.

\section{Método de Pesquisa}

Para responder ao problema proposto, desenvolveu-se uma pesquisa de abordagem qualitativa. De acordo com Minayo (2010), este tipo de pesquisa responde a questões muito particulares, como crenças, valores e atitudes, correspondendo a um espaço mais profundo dos fenômenos, não podendo estes serem reduzidos à operacionalização de variáveis. Pratt (2009) afirma que a pesquisa qualitativa é mais adequada para responder perguntas "como", para entender o mundo pela perspectiva do informante e para examinar processos de articulação.

No que tange aos objetivos do presente estudo, o mesmo é classificado como de cunho exploratório, a fim proporcionar maior conhecimento através do problema e torná-lo mais explícito, conforme leciona Gil (2007). Para sua realização adotou-se os seguintes procedimentos: realização de pesquisa bibliográfica a partir do levantamento de referências teóricas já analisadas, visando possibilitar ao pesquisador o que já foi estudado sobre a temática abordada, desta forma caracterizada por Fonseca (2002); e pesquisa de campo, a qual, segundo Oliveira (2011), é caracterizada pela observação de fatos e fenômenos tal como ocorrem de forma espontânea, e tem por objetivo gerar dados e conhecimento a cerca de um problema, para o qual se procura uma resposta.

A técnica de coleta de dados utilizada para a presente pesquisa foi a entrevista semiestruturada. Triviños (1987) argumenta que este tipo de entrevista é caracterizado pela adoção de questionamentos básicos, apoiados em teorias e hipóteses (que interessam à pesquisa) e que, em seguida, oferecem amplo campo de interrogativas, frutos de novas hipóteses que vão surgindo à medida que se recebem as respostas do informante; além de proporcionar todas as perspectivas possíveis para que o informante da liberdade necessária ao enriquecimento da investigação.

Os sujeitos da pesquisa são dez docentes, de universidades públicas do estado do Rio de Janeiro - ao menos dois de cada - que possuem o curso de Ciências Contábeis, e que ministram 
disciplinas voltadas ao estudo das normas de contabilidade financeira. Constituem as referidas universidades: Universidade do Estado do Rio de Janeiro (UERJ), Universidade Federal do Rio de Janeiro (UFRJ), Universidade Federal Rural do Rio de Janeiro (UFRRJ) e Universidade Federal Fluminense (UFF).

A coleta de dados foi realizada no período compreendido entre 29 de junho de 2017 a 13 de julho do mesmo ano, por meio de entrevistas semiestruturadas realizadas de forma presencial, gravadas e transcritas na íntegra. No quadro 2, a seguir, são explicitadas as questões que compuseram o roteiro de entrevistas, elaborado por estes pesquisadores, assim como os objetivos da inserção de tais pontos no instrumento de coleta.

Quadro 2 - Roteiro de entrevistas semiestruturadas

\begin{tabular}{|l|l|}
\hline \multicolumn{1}{|c|}{ Questão } & \multicolumn{1}{c|}{ Objetivo } \\
\hline $\begin{array}{l}\text { De que forma vê a interdisciplinaridade no ensino } \\
\text { contábil no presente momento? }\end{array}$ & $\begin{array}{l}\text { Compreender de que forma ocorre a } \\
\text { interdisciplinaridade no curso de Ciências Contábeis. }\end{array}$ \\
\hline $\begin{array}{l}\text { Que outras áreas do saber, ademais da própria } \\
\text { contabilidade, considera relevante para a formação do } \\
\text { contador? }\end{array}$ & $\begin{array}{l}\text { Identificar que áreas do saber são relevantes para a } \\
\text { formação do futuro profissional contábil. }\end{array}$ \\
\hline $\begin{array}{l}\text { Qual sua percepção acerca da inserção de disciplinas } \\
\text { de cunho filosófico na grade curricular do curso de } \\
\text { Ciências Contábeis? }\end{array}$ & $\begin{array}{l}\text { Analisar o entendimento dos respondentes sobre a } \\
\text { presença de disciplinas relacionadas à Filosofia no } \\
\text { curso de contabilidade. }\end{array}$ \\
\hline $\begin{array}{l}\text { Percebe um senso crítico, por parte dos discentes, para } \\
\text { com as normas contábeis apresentadas a eles? }\end{array}$ & $\begin{array}{l}\text { Identificar de que forma, criticamente ou } \\
\text { acriticamente, os alunos reagem às normas contábeis } \\
\text { apresentadas a eles no decorrer do curso. }\end{array}$ \\
\hline $\begin{array}{l}\text { Observa maiores dificuldades, por parte dos alunos, } \\
\text { com relação ao aprendizado e aplicação de conceitos } \\
\text { relacionados ao subjetivismo contábil? }\end{array}$ & $\begin{array}{l}\text { Compreender se os discentes de contabilidade } \\
\text { possuem maiores dificuldades em relação ao } \\
\text { aprendizado de conceitos de natureza subjetiva. }\end{array}$ \\
\hline $\begin{array}{l}\text { Acredita que o discente de graduação em Ciências } \\
\text { Contábeis é preparado para lidar com uma } \\
\text { contabilidade baseada em princípios? }\end{array}$ & $\begin{array}{l}\text { Analisar se os alunos do curso de graduação em } \\
\text { Ciências Contábeis têm uma formação que, de fato, os } \\
\text { prepara para lidar com o subjetivismo contábil. }\end{array}$ \\
\hline
\end{tabular}

Fonte: Elaborado pelos autores.

O instrumento de coleta de dados, explicitado no quadro 2, foi elaborado com base tanto em pesquisas nas quais demonstrou-se a relevância da interdisciplinaridade para fins de estímulo ao senso crítico de discentes de Ciências Contábeis e áreas correlatas (BASTOS; PELEIAS, 2017; CAGGY; FISCHER, 2014; PELEIAS et al., 2011) quanto acerca da necessidade do estímulo à criticidade a fim de que tais futuros profissionais possam lidar com o subjetivismo contábil presente nas normas internacionais de contabilidade e, assim, ao perfil que passou a ser exigido do contador a partir da adoção das referidas normas (ESPEJO et al., 2010a; FIORENTIN; DOMINGUES, 2012; SILVA et al., 2011).

Com relação à análise dos dados, utilizou-se a técnica de análise de conteúdo, definida por Bardin (2009) como um conjunto de técnicas de análise das comunicações que visam obter, por meio de métodos sistemáticos e objetivos de descrições das mensagens, indicadores que permitam inferir conhecimentos relativos à produção de tais mensagens. Ainda segundo a mesma autora, há três grandes métodos de análise de conteúdo, sendo eles: análise temática ou categorial, análise formal e análise estrutural.

Na presente pesquisa empregou-se a análise temática, que de acordo com Bardin (2009), visa revelar as avaliações dos locutores acerca de um tema a partir do exame de certos elementos que compõem o discurso, como a frequências dos temas, avaliação de juízos, etc. No que diz respeito à sua operação, a análise temática de conteúdo consiste nas seguintes etapas: pré-análise, onde é realizada a transcrição dos áudios e leitura flutuante das transcrições; exploração do material, no qual são realizadas as categorizações; e tratamento dos dados, consistindo na interpretação dos dados empíricos obtidos e o marco teórico utilizado (MINAYO, 2010).

No que concerne à exploração do material, Bardin (2009) declara que as categorias podem 
ser criadas a priori, ou seja, com base na teoria, ou a posteriori, a partir da análise dos dados obtidos. Na presente pesquisa optou-se pela categorização a posteriori, seguindo sugestão de Mendes (2007), a qual defende que a categorização deve ser sempre criada com base nos conteúdos verbalizados e com certo refinamento gramatical. Após audição e leitura sistemática das entrevistas realizadas, emergiram as seguintes categorias para fins de análise dos dados obtidos com as entrevistas: interdisciplinaridade, raciocínio crítico, elementos filosóficos aplicados à contabilidade e, por fim, educação contábil e contabilidade baseada em princípios.

Ademais, utilizou-se o software QSR NVIVO 11, com objetivo de apontamento de pontos semelhantes e divergentes entre as respostas concedidas pelos entrevistados, assim como na estruturação das categorias utilizadas.

\section{Análise dos Resultados}

Consoante descrito no capítulo referente à metodologia foram realizadas entrevistas com docentes que ministram disciplinas que abordam as normas contábeis nos cursos de graduação em Ciências Contábeis oferecidas pelas universidades públicas do Estado do Rio de Janeiro, visando avaliar a percepção dos mesmos sobre a relevância da filosofia para a formação do contador, especialmente sobre a tomada de decisão sob a vigência das IFRS. As categorias de análise identificadas, que advieram da triangulação das falas, serão apresentadas nos tópicos a seguir.

\subsection{Interdisciplinaridade}

A primeira categoria visa avaliar a percepção dos docentes entrevistados com relação à relevância da interdisciplinaridade para o curso de graduação em Ciências Contábeis, como essa questão está sendo trabalhada atualmente no referido curso e quais áreas poderiam ser melhores exploradas no âmbito da graduação.

Todos os docentes entrevistados foram unânimes em destacar a importância da interdisciplinaridade para a formação do contador. Tal posição pode ser confirmada pelas palavras do entrevistado número sete:

Bem, há necessidade de ter disciplinas diversas na grade, de ter comunicação com outras áreas de conhecimento, visto, sobretudo, já entrando um pouco nas IFRS, porque a gente tem um grau de subjetividade muito grande, então o profissional de contabilidade precisa estar a par de um conhecimento mais amplo que não necessariamente só técnico-contábil, né, para poder tomar as decisões, já que basicamente vai tomar para si uma responsabilidade maior. Então, a importância dessa interdisciplinaridade é preparar esse profissional para as várias situações que vai se deparar ao longo da carreira, ao longo do trabalho (Entrevistado 07).

A percepção dos docentes converge com os estudos realizados por Laffin (2004), Padoan e Clemente (2006) e Peleias et al. (2011), os quais ressaltaram a relevância do tema para o curso de graduação em Ciências Contábeis.

Acerca da existência de interdisciplinaridade na graduação em Ciências Contábeis, a maioria dos entrevistados defende que a mesma existe, ainda que focada em áreas correlatas à contabilidade e que ainda há espaço para ser melhor trabalhada. Opinião distinta possui o entrevistado número quatro, que discorre:

A interdisciplinaridade aparece nas diretrizes curriculares do MEC para o curso de Contábeis, e para mim não existe isso no ensino da contabilidade, sendo vários os fatores. Mas acho que o principal é a falta de entrosamento do corpo docente dos cursos de Ciências Contábeis, e isso por diversos fatores, sendo que pesquisas trazem os porquês disso; como nas particulares, em que a quantidade de horistas é bem grande, e nas públicas, onde há uma falta de entrosamento nos professores em grupos de pesquisas, por cada um querer pesquisar sobre seu tema, além de cada pesquisar ao seu modo, e gostar muito de sua autonomia, então, quer dizer, há vários fatores que explicam os motivos de 
não haver interdisciplinaridade. (Entrevistado 04)

O entendimento dos entrevistados, de que o tema necessita ser melhor e mais abordado na graduação, coincide com as pesquisas operadas por Passos (2004) e Cabral et al. (2011), as quais mostram que poucas características interdisciplinares são notadas nas ementas dos cursos de graduação em Ciências Contábeis.

Outro ponto destacado pelos docentes foi a dificuldade de demonstrar a relevância de disciplinas interdisciplinares para os discentes no que concerne sua formação na contabilidade, fato demonstrado pelo posicionamento do entrevistado número cinco:

A questão é como essa interdisciplinaridade é levada pros alunos, porque quando, por exemplo, você tem uma aula estatística, dentro de um curso de ciências contábeis, o ideal é que você mostre para o aluno como é a aplicabilidade daquela estatística para o curso dele, mas muito das vezes não é isso que ocorre, porque o professor que está dando aula de estatística, ele é um estatístico e ele as vezes dá aula como se estivesse dando para um curso de estatística, então essa é a grande dificuldade; e a gente pode colocar isso para todas as disciplinas: microeconomia, macro, disciplinas de administração, então, é... esse é o grande problema, e aí o aluno, ele acaba não conseguindo fazer essa ligação: "para que que eu tenho que estudar isso, se isso não é contabilidade?”. (Entrevistado 05)

Nota-se que os docentes entrevistados consideram a interdisciplinaridade relevante para o curso de Ciências Contábeis, embora não seja notada de forma suficiente nos cursos de graduação. Ademais, destaca-se a necessidade de mostrar ao discente a importância das disciplinas nãocontábeis. Com relação às disciplinas interdisciplinares ressaltadas pelos professores, destacam-se as ligadas às áreas de Administração, Economia, Sociologia, Filosofia, ao Direito e Matemática.

Conforme o exposto nesta subseção e, ainda, com base em estudos correlatos (BASTOS; PELEIAS, 2017; CAGGY; FISCHER, 2014), a inserção de disciplinas de outras áreas do saber no âmbito da formação do contador tende a agregar à formação dos discentes da área, ao apresentálos a novas perspectivas, as quais poderão ser aplicadas por tais sujeitos tanto no âmbito profissional quanto no pessoal.

\subsection{Raciocínio Crítico}

Esta categoria objetivou analisar a opinião dos professores entrevistados sobre a existência de atitudes críticas por parte de seus discentes para com as normas contábeis apresentadas a eles. Oito entrevistados afirmaram não perceber tais atitudes críticas, tendo os outros dois optado por não responder à pergunta. A opinião majoritária é exemplificada pelo posicionamento do entrevistado número três.

Não, é triste responder isso, mas não. Você quer ver a sala ficar em silêncio é quando você faz uma pergunta, e aí a sala fica em silêncio, e eu costumo brincar: Tem alguém aí? Porque, eu não sei, é engraçado que um ou outro você consegue provocar, estimular uma pergunta, e eu gostaria que isso fosse um problema só da universidade onde eu leciono, mas conversando com outros colegas eu percebo que isso não é, e isso entristece. (Entrevistado 03)

Quando questionados sobre sua percepção acerca dos motivos que causam essa falta de posicionamento crítico por parte dos seus discentes, nota-se ênfase no histórico tecnicista do curso de Ciências Contábeis e a abordagem fiscal adotada pelos discentes para com as normas contábeis. Tais opiniões são demonstradas pela fala do entrevistado número nove:

Eles reclamam que as normas deixam uma responsabilidade muito grande para o contador, para o profissional julgar o que precisa ser feito. E antes a gente tinha uma estrutura, antes da introdução do IFRS, que era tudo muito manualizado, tudo estava em uma tabela. Se você tinha uma dúvida você ia lá e consultava o artigo de um manual e ele ia te dizer o que fazer, como proceder, diante de determinado fato ou transação. Algumas normas das IFRS são muito mais abertas e aí transferem para o contador a 
responsabilidade do tratamento de determinado fenômeno. E os alunos sentem essa responsabilidade vindo para eles enquanto futuros profissionais, e eles não gostam disso. (Entrevistado 09)

Inquiridos sobre quais temáticas concernentes às IFRS se mostram mais dificultosas para seus discentes, ressaltam questões que exigem análise crítica dos mesmos para sua correta utilização, conforme destacado pelo docente número oito:

Em resumo: valor justo, impairment, essência sobre a forma, as premissas que você precisa para fazer estimativas; pois você fala disso e o pessoal já pensa em base histórica, mas e as outras? Eu não tenho ministrado contabilidade avançada agora, mas uma outra questão era a de passivo contingente, que o pessoal fica com muita dificuldade. (Entrevistado 08)

Não foram encontrados estudos acerca da percepção de docentes sobre o raciocínio crítico de seus discentes na literatura contábil; contudo, estudos correlatos, como o realizado por Cornacchione JR; Duncan e Johson (2007), concluíram que os discentes de Ciências Contábeis analisados em sua amostra possuíam elevados níveis de raciocínio crítico, o que diverge da percepção dos docentes participantes desta pesquisa, embora tal divergência possa ser explicada pela adoção às normas contábeis internacionais.

Nesse sentido, entende-se, por parte destes autores, que sugestões advindas de estudos como o realizado por Murcia et al. (2015), no qual os pesquisadores recomendam que os cursos de contabilidade no Brasil tenham seus programas revisados, a fim de terem adicionadas disciplinas e temáticas que fujam do escopo puramente tecnicista no âmbito do curso, poderiam agregar no que toca ao estimulo à criticidade dos discentes da seara.

\subsection{Elementos filosóficos aplicados à contabilidade}

A terceira categoria busca avaliar o entendimento dos docentes entrevistados sobre a presença de pressupostos filosóficos, assim como de disciplinas filosóficas na grade de Ciências Contábeis - como Filosofia da Ciência, disciplina recomendada pelo CFC, na proposta de matriz curricular para os cursos de Ciências Contábeis do ano de 2009 - e qual seria a relevância de tais temáticas na ementa do curso de graduação em contabilidade.

Acerca da relevância de disciplinas filosóficas na ementa da graduação, todos os professores participantes desta pesquisa afirmaram que as mesmas teriam impacto positivo na formação do futuro profissional contábil, desde que fossem aplicadas à contabilidade; opinião destacada na fala do entrevistado número oito:

Eu acho que impactaria sim, penso que é importante desenvolver esse tipo de disciplina, que é uma muito importante [...]. Quando você fala de filosofia da ciência, há uma discussão sobre coisas mais críticas, fazer uma análise de situação, discorrer sobre um determinado assunto, e isso é útil para sua vida profissional, mas não é uma coisa pontual e imediata, e sim mais para frente, e eu acho que falta uma visão no pessoal de perceber isso, então acaba acontecendo o que ocorre com a disciplina teoria da contabilidade, que as pessoas associam a teoria com algo que é muito distante da prática, o que é uma total incoerência, visto que você só pratica corretamente por ter os conceitos teóricos. (Entrevistado 08)

Não foram encontrados trabalhos que analisam a opinião de docentes sobre a temática exposta; contudo, o entendimento dos professores entrevistados coaduna com os resultados obtidos em pesquisas correlatas, como a realizada por Trombetta e Trombetta (2015), na qual questionaram discentes e profissionais da área contábil sobre a relevância da filosofia e sociologia na graduação em Ciências Contábeis, tendo concluído que os mesmos entendem que tais áreas agregam conhecimentos primordiais para a formação do contador.

Com relação aos motivos pelos quais disciplinas filosóficas não são geralmente 
encontradas no curso de contabilidade, os educadores indicam a dificuldade em encontrar professores de Filosofia que abordem a temática com viés contábil, ou mesmo docentes de contabilidade que estejam aptos para ministrar questões filosóficas na área contábil, conforme explicitado na fala do entrevistado número seis:

[...] a gente até tem disciplinas de filosofia mas a gente tem muita dificuldade por conta do departamento de filosofia ter outras mentalidades; eles passam a Filosofia como é pra um filósofo, então fica muito difícil pro contador, né, pro aluno que chega entender, ainda mais por ser um aluno de início de período. (Entrevistado 06)

Ainda no que concerne tal questão, há o entendimento de que o pragmatismo e o viés majoritariamente tecnicista existente no curso de Ciências Contábeis dificultaria a inclusão de disciplinas interdisciplinares, como aquelas que abordam a Filosofia, exposto no posicionamento do entrevistado número dez:

Hoje os cursos têm adotado uma postura mais pragmática, mais tecnicista na nossa era, né, de tudo muito rápido, de produzir mais bacharéis, e acaba sendo um caminho perigoso, porque você prejudica muitos pontos pra uma formação mais abrangente e na questão da interdisciplinaridade [...]. (Entrevistado 10)

Acerca da importância de pressupostos filosóficos na formação do contador, como a ética, todos os participantes ressaltaram a necessidade da temática ser abordada na graduação, embora entendam que seja algo além do âmbito acadêmico, conforme citado pelo entrevistado número seis:

[...] o impacto claro que é grande, apesar de considerar que a pessoa tem que vir com a ética própria, não sei, ajuda né, você tem um curso, ter uma disciplina, ajuda, mas acho que a ética vem da própria pessoa, a pessoa que é honesta ela vai ser honesta, simples. (Entrevistado 06)

O entendimento dos docentes condiz com a pesquisa de Martinov-bennie e Mladenovic (2015), na qual os autores concluíram que o ensino de ética a nível de graduação auxilia na prática do julgamento ético por parte dos discentes e, consequentemente, futuros profissionais.

Com base no exposto, destaca-se que a Filosofia possui relações conceituais compartilhadas com a Ciência Contábil (MARTINS, 2012; SILVA, 2014) e, portanto, somandose ao que fora explicitado nesta subseção, entende-se sua aplicação no âmbito da formação do contador é possível, embora possua desafios para que seja, de fato, implementada.

\subsection{Educação contábil e contabilidade baseada em princípios}

A quarta e última categoria versa sobre o atual momento da educação contábil sobre o que pensam os docentes entrevistados sobre o atual momento da educação contábil no Brasil, mais precisamente, se de fato o discente é preparado para lidar com a contabilidade baseada em princípios advinda da adoção às normas internacionais.

Oito dos dez professores acreditam que o discente em contabilidade no Brasil não é devidamente preparado para lidar com o subjetivismo contábil advindo das IFRS. As principais razões para tal deficiência estariam ligadas à pouca oferta de programas de pós-graduação em Ciências Contábeis - e consequentemente a pouca oferta de mestres e doutores -, o viés tecnicista de muitas instituições de ensino e a herança normativa que ainda permearia certos âmbitos da área contábil. Ademais, os altos níveis de reprovação no exame de suficiência são citados como constatação de tal ponto de vista, citado pelo entrevistado número quatro:

Olha, minha hipótese é que não, e eu acho que temos um pouco de comprovação com o exame de suficiência [...]. Então eu acho que não há esse preparo, pois muitos contadores vivem naquela contabilidade de regras mesmo, antigas e tudo mais, e isso porque é um curso muito voltado para o mercado, aí no mercado a maioria não é grande empresa, e se você pegar os mais de 1400 cursos de contábeis no Brasil a maioria dos alunos vai para 
escritório, né, pequena e média empresa, e nos escritórios a maioria faz simples e presumido, ou seja, é um despachante tributário, não faz contabilidade, pega uma folha de pagamento, aprende parte legal de abertura e encerramento de empresa e é isso aí; então a realidade prática é uma realidade muito técnica ainda. (Entrevistado 04)

Tal ponto de vista não é compartilhado por outros dois professores, os quais comentam que há esse preparo, ainda que o mesmo esteja em processo de evolução e necessite ser melhorado, conforme explanado pelo entrevistado número cinco:

[...] foi uma convergência muito forçada, nossa, foi muito difícil, está sendo muito difícil. A gente não teve um período de adaptação, foi tudo na marra de uma hora pra outra, então isso também é muito difícil, também têm professores muito antigos nas universidades, que não se atualizam, não conseguem se atualizar, e você vai fazer o que, sabe, não tem muita coisa a fazer, então, a gente ainda tem muitos problemas, mas eu... eu vejo de forma muito positiva porque acho que a gente já avançou bastante do que a gente tinha antes, sabe. (Entrevistado 05)

As opiniões divergentes por parte dos professores entrevistados estão de acordo com os resultados encontrados nos estudos realizados Espejo et al. (2010b), Bemfica et al. (2016) e Fonteles, Oliveira e Almeida (2011); os quais indicam que ainda há dificuldades no processo de capacitação do corpo docente e preparo de discentes para com às normas contábeis, embora sejam notadas melhoras significativas em comparação há anos recentes e, dessa forma, entende-se que adoção de novas perspectivas à formação dos futuros profissionais contábeis poderá agregar em tal sentido.

\section{Conclusões}

Este estudo buscou investigar a percepção de docentes, que ministram disciplinas que abordam as IFRS a nível de graduação nos cursos de Ciências Contábeis oferecidos nas universidades públicas do estado do Rio de Janeiro, acerca da possível relevância da Filosofia para a formação do contador, mais precisamente no que toca à tomada de decisão sob a vigência das IFRS.

Os resultados obtidos após análise das entrevistas indicam que, na percepção dos entrevistados, a Filosofia, por meio de disciplinas que abordam seus pressupostos e conceitos, é relevante e agrega positivamente para a formação do futuro profissional contábil, visto que auxilia os discentes no que tange a lidar com o subjetivismo advindo da adoção às normas internacionais de contabilidade, além de estimular a criticidade dos mesmos.

Além da Filosofia em si, foram abordados temas correlatos e pertinentes, como a questão da interdisciplinaridade, que foi considerada importante à formação do futuro profissional contábil, além de ressaltar-se que a mesma necessita ser melhor explorada na graduação. Ainda sobre esta temática, discorreu-se acerca de áreas pertinentes ao ensino contábil, tendo destaque a Administração, a Economia, o Direito, a Sociologia, a Matemática e a Filosofia.

Inquiriu-se, também, sobre a atitude crítica de discentes com relação às normas contábeis que são apresentadas a eles, tendo-se averiguado que tais atitudes não são percebidas. Os entrevistados apontam que a citada falta de atitude crítica, assim como a pouca presença de disciplinas que auxiliam no processo de desenvolvimento desta, como a Filosofia, é resultante dos vieses tecnicistas e fiscais existentes no curso de Ciências Contábeis.

Com relação às temáticas concernentes às IFRS que são consideradas complexas por parte dos discentes e geram maiores dificuldades aos mesmos, ressalta-se: teste de impairment, valor justo, essência sobre a forma, estimativas, passivos contingentes e outros temas que exigem julgamento por parte do profissional contábil.

O atual momento da educação contábil no Brasil foi analisado pelos entrevistados, os quais, em sua maioria, concluíram que não há um devido preparado do discente para lidar com questões 
que exigem julgamento por parte do profissional. Tal fato seria corroborado pelos altos índices de reprovação no exame de suficiência, que tem exigido cada vez mais análise crítica por parte daqueles que o realizam.

Portanto, conclui-se que a Filosofia, ainda que seja uma área de conhecimento extremamente antiga, é pertinente no que se refere à formação do contador sob a vigência das IFRS, visto que essas exigem capacidade de julgamento do profissional contábil para lidar com sua subjetividade e, portanto, tal característica é esperada por parte dos contadores a partir da adoção das normas contábeis internacionais. Contudo, denotam-se dificuldades para o ensino e utilização da mesma nos cursos de graduação em Ciências Contábeis, como dificuldades em contratar docentes de contabilidade que entendam da temática ou, ainda, filósofos que abordem a contabilidade; assim como o desafio de demonstrar aos discentes a importância de tal seara para seu futuro como contador.

Diante do exposto, entende-se que esta pesquisa apresentou contribuições em ao menos três esferas distintas: teórica - ao agregar à lacuna investigativa científica referente às relações existentes entre preceitos filosóficos e a seara contábil (MARTINS, 2012; SILVA, 2014); prática - pois, ao evidenciar que, sob a ótica de docentes de contabilidade, o ensino de preceitos da Filosofia no âmbito da formação do futuro profissional contábil possui influência positiva no que tange uma melhor aderência ao que é esperado do novo perfil do contador (ESPEJO et al., 2010a; FUJI; SLOMSKI, 2003) e, assim, espera-se que os sujeitos relacionados ao curso de graduação em Ciências Contábeis, tais como coordenadores e docentes, passem a considerar tal perspectiva no processo de ensino-aprendizagem dos discentes do curso; e social - visto que ao demonstrar a pertinência da Filosofia para o ensino em contabilidade, entende-se que alunos do curso de graduação poderão ter maiores possibilidades de contato com óticas relacionadas ao estímulo de sua criticidade e subjetividade enquanto sujeitos inseridos em distintas estruturas sociais (CABRAL; SIQUEIRA; SIQUEIRA-BATISTA, 2011; LAFFIN, 2004; MALUSÁ et al., 2015).

As limitações do presente estudo estão relacionadas ao entendimento dos sujeitos da pesquisa, ao responderem o instrumento de coleta de dados, com relação ao que percebem como sendo os aspectos abordados nas questões do citado instrumento; contudo, entende-se que, ao adotar um roteiro semiestruturado, tal limitação foi, em parte, mitigada.

Por fim, sugere-se que futuros estudos que abordem o tema visem avaliar a percepção dos demais sujeitos envolvidos no processo de formação no âmbito contábil, como coordenadores de curso e discentes, tanto de graduação quanto de programas de pós-graduação, acerca da relevância da Filosofia e outras áreas para a formação do profissional contábil.

\section{Referências}

ABBAGNANO, N. Diccionario de filosofía. Buenos Aires: Fondo de Cultura Económica, 1963.

ARAÚJO, A. P. M. Currículos dos cursos de Ciências Contábeis das Universidades Federais Brasileiras: uma análise de adequação à proposta nacional de conteúdo do Conselho Federal de Contabilidade e o desempenho dessas IFES no ENADE. 2015. Trabalho de Conclusão de Curso. Universidade Federal do Rio Grande do Norte.

BARDIN, L. Análise de Conteúdo. Lisboa: Edições, 2009.

BASTOS, A. M. R.; PELEIAS, I. R. Interdisciplinaridade no ensino de perícia contábil: percepção dos professores em cursos de Ciências Contábeis na cidade de São Paulo. In: Congresso ANPCONT, 11., 2017. Anais... Congresso ANPCONT, 2017. 
BAZANINI, R.; Zanuto, R.; Bazanini, H. L. O Ensino de Filosofia nos Cursos de Administração. Uma Abordagem Crítica da Educação Tradicional. In: XII Semead, 2009, São Paulo. Anais... XII Semead - Seminários em Administração, 2009, v.1.

BEMFICA, M. F. C. et al. Convergência às Normas Internacionais e o Ensino da Contabilidade: Uma Análise sob a Ótica dos Coordenadores dos Cursos de Ciências Contábeis de Pernambuco. RAGC, v. 4, n. 12, 2016.

BRAGA, J. P. et al. Análise do impacto das mudanças nas normas contábeis brasileiras: um estudo comparativo dos indicadores econômico-financeiros de companhias brasileiras para o ano de 2007. Revista Contemporânea de Contabilidade, v. 8, n. 15, p. 105-128, 2011. https://doi.org/10.5007/2175-8069.2011v8n15p105

CABRAL, I.; SIQUEIRA, J. R. M.; BATISTA, R. S. O diálogo das ciências contábeis com as ciências humanas e demais ciências sociais: uma análise da produção acadêmica do Congresso USP de Controladoria e Contabilidade e Enanpad (2004-2007). Revista de Educação e Pesquisa em Contabilidade (REPeC), v. 5, n. 0, p. 100-125, 2011. Disponível em: http://repec.org.br/index.php/repec/article/viewFile/162/361. Acesso em: 20 jul. 2017.

CAGGY, R.C.S.S; FISCHER, T.M.D. Interdisciplinaridade revisitada: analisando a prática interdisciplinar em uma faculdade de administração da Bahia. Revista Administração: ensino e pesquisa, v. 15, n. 3, p. 501-531, 2014. https://doi.org/10.13058/raep.2014.v15n3.12

CHAUÍ, M. Convite à Filosofia. São Paulo: Ática, 2001.

CORNACCHIONE JR., E. B.; DUNCAN, J.; JOHNSON, S. D. Critical Thinking Skills of Accounting Students: Habilidade de Raciocínio Crítico de Alunos de Contabilidade. Revista de Educação e Pesquisa em Contabilidade, v.1, n.2, art.3, p.43-70. Mai/Ago, 2007. Disponível em: http://www.repec.org.br/index.php/repec/article/view/9/10. Acesso em: 01 ago. 2017.

COSTA, T. A.; ALMEIDA, S. R. V.; SILVA, A. H. C. Uma análise dos impactos da adoção das normas internacionais de contabilidade no Brasil: um estudo de empresas de capital aberto no setor de bebidas, alimentos e comércio. Pensar Contábil, v. 15, n. 56, 2013. Disponível em: http://www.atena.org.br/revista/ojs-2.2.3-08/index.php/pensarcontabil/article/view/1539. Acesso em: 20 jun. 2017.

CONSELHO FEDERAL DE CONTABILIDADE - CFC. Proposta nacional de conteúdo para o curso de graduação em Ciências Contábeis. Brasília, 2009.

DIEHL, C. A.; FREITAS, A. C.; MACAGNAN, C. B. A percepção sobre ética de estudantes de curso de graduação em Ciências Contábeis. Revista de Educação e Pesquisa em Contabilidade (REPeC), v. 5, n. 1, p. 21-49, 2011. Disponível em:

http://www.repec.org.br/index.php/repec/article/view/228/99. Acesso em: 10 set. 2017.

ESPEJO, M. et al. Uma Abordagem Institucional Do Subjetivismo Responsável Na Adoção Das Normas Internacionais De Contabilidade: Uma Análise Crítico-Reflexiva sobre os inibidores à convergência no Brasil. Revista Estudos do ISCA, p. 1-23, 2010a. Disponível em: http://revistas.ua.pt/index.php/estudosdoisca/article/view/804/pdf. Acesso em: 28 jun. 2017.

ESPEJO, M. et al. Evidências empíricas do ensino no curso de ciências contábeis: uma análise 
das respostas às alterações provenientes da Lei 11.638/07. Revista de Contabilidade do Mestrado em Ciências Contábeis da UERJ, Rio de Janeiro, v. 15, n. 1, p.22-39, 2010b. Disponível em: http://www.atena.org.br/revista/ojs-2.2.3-

08/index.php/UERJ/article/view/886/846. Acesso em: 11 nov. 2017.

FIORENTIN, M.; DOMINGUES, M. J. C.. Interdisciplinaridade no curso de Ciências Contábeis: um estudo na Universidade de Passo Fundo-RS. ConTexto, v. 12, n. 21, p. 7-16, 2012.

FONSECA, J. J. S. Metodologia da pesquisa científica. Universidade Estadual do Ceará. Fortaleza, 2002.

FONTELES, I. V.; OLIVEIRA, M. C.; ALMEIDA, S. R. Medidas adotadas pelas IFES brasileiras visando a qualificação docente e a adequação de conteúdos com as novas práticas contábeis. In: Congresso USP de Iniciação Científica, 8., 2011. Anais... Congresso USP de Iniciação Científica, 2011.

FUJI, A. H.; SLOMSKI, V. Subjetivismo Responsável: necessidade ou ousadia no estudo da Contabilidade. Revista Contabilidade \& Finanças - USP, n.33, p.33-44, São Paulo, 2003. Disponível em: https://www.revistas.usp.br/rcf/article/view/34109/36841. Acesso em: 15 ago. 2017.

GERON, C. M. S. Evolução das práticas contábeis no Brasil nos últimos 30 anos: da lei 6.404/76 à lei 11.638/07. 2008. Dissertação (Mestrado em Controladoria e Contabilidade) Departamento de Contabilidade e Atuária da Universidade de São Paulo, São Paulo. 2008.

GIL, A. C. Métodos e técnicas de pesquisa social. 6. ed. São Paulo: Atlas, 2007.

HOOG, W. A. Z. Filosofia aplicada à contabilidade. 1. ed. Curitiba: Juruá, 2013.

IUDÍCIBUS, S. et al. Manual de contabilidade das sociedades por ações: aplicável às demais sociedades. 1. ed. São Paulo: Atlas, 2010.

LACERDA, D. P. Cultura organizacional: sinergias e alergias entre Hofstede e Trompenaars. Revista de Administração Pública, v. 45, n. 5, p. 1285-1301, 2011. https://doi.org/10.1590/S0034-76122011000500003

LAFFIN, M. Projeto Político-pedagógico nos Cursos de Ciências Contábeis. Revista Brasileira de Contabilidade. São Paulo. Jul-ago. 2004.

LEMES, S.; CARVALHO, L. N. G. Comparabilidade entre o resultado em BR GAAP e U.S. GAAP: evidências das companhias brasileiras listadas nas bolsas norte-americanas. Revista Contabilidade \& Finanças, v. 20, n. 50, p. 25-45, 2009. Disponível em: http://www.revistas.usp.br/rcf/article/view/34289/37021. Acesso em: 19 set. 2017.

MACEDO, M. A. S. et al. Impacto da Convergência às Normas Contábeis Internacionais no Brasil Sobre o Conteúdo Informacional da Contabilidade. Revista de Educação e Pesquisa em Contabilidade, v. 7, n. 3, p. 222-239, 2013. Disponível em: http://www.repec.org.br/index.php/repec/article/view/905/762. Acesso em: 10 jun. 2017. 
MAGRO, C. B.; SILVA, T. B. S.; ZONATTO, V. C. S. Como discentes de Ciências Contábeis reagem à dilemas éticos da profissão?. Contabilidade Vista \& Revista, v. 28, n. 3, p. 53-81, 2017.

MALUSÁ, Silvana. et al. Ensino superior: concepções de pedagogia universitária no curso de ciências contábeis. Revista Educação e Cultura Contemporânea, v. 12, n. 27, p. 289-319, 2015.

MARTINOV-BENNIE, N.; MLADENOVIC, R. Investigation of the impact of an ethical framework and an integrated ethics education on accounting students' ethical sensitivity and judgment. Journal of Business Ethics, v. 127, n. 1, p. 189-203, 2015.

https://doi.org/10.1007/s10551-013-2007-5

MARTINS, E. A. Pesquisa contábil brasileira: uma análise filosófica. Tese (Doutorado em Ciências Contábeis), Faculdade de Economia, Administração e Contabilidade, Universidade de São Paulo, São Paulo, 2012.

MENDES, A. M. (Org.). Psicodinâmica do trabalho: teoria, método, pesquisas. São Paulo: Casa do Psicólogo, 2007.

MINAYO, M. C. S. Pesquisa social teoria, método e criatividade. 29. ed. Petrópolis, RJ Vozes, 2010.

MOTA, R. H. G. et al. Normas baseadas em princípios e regras: Uma análise comparativa das normas do IASB e FASB. Revista Ambiente Contabil, v. 8, n. 2, p. 19, 2016. Disponível em: https://periodicos.ufrn.br/ambiente/article/view/8533. Acesso em: 02 ago. 2017.

MURCIA, F. C. S. et al. Accounting undergraduate curriculum: a comparison between Brazil, the USA and the UK. International Journal of Auditing Technology, v. 2, n. 3, p. 269-287, 2015. https://doi.org/10.1504/IJAUDIT.2015.070539

NASCIMENTO, C. et al. O tema ética na percepção dos alunos de graduação de Ciências Contábeis em universidades da região Sul do Brasil. Revista Contemporânea de Contabilidade, v. 7, n. 14, p. 75-96, 2011. https://doi.org/10.5007/2175-8069.2010v7n14p75

NIYAMA, J. K. Contabilidade Internacional. 2. ed. São Paulo Atlas: 2010.

OLIVEIRA, A. B. Métodos de Pesquisa Contábil. São Paulo: Atlas, 2011.

OLIVEIRA, A. B. et al. Métodos e técnicas de pesquisa em contabilidade. São Paulo: Saraiva, 2003.

OLIVEIRA, N. A. L. et al. Regulação contábil no Brasil: uma análise dos processos de audiência pública do comitê de pronunciamentos contábeis (CPC) nos anos de 2007 a 2011. Advances in Scientific and Applied Accounting, v. 6, n. 1, p. 49-65, 2013. Disponível em: http://www.atena.org.br/revista/ojs-2.2.3-08/index.php/ASAA/article/view/1760. Acesso em: 12 jun. 2017.

PADOAN, F. A. C.; CLEMENTE, A. A interdisciplinaridade no ensino da Contabilidade um estudo empírico da percepção dos docentes. In: CONGRESSO USP DE CONTROLADORIA E 
CONTABILIDADE, n. 06, 2006, São Paulo. Anais... São Paulo.

PASSOS, I. C. A interdisciplinaridade no ensino e na pesquisa contábil: um estudo no município de São Paulo. Dissertação (Mestrado em Controladoria e Contabilidade) - Faculdade de Economia, Administração e Contabilidade, Universidade de São Paulo, São Paulo, 2004.

PAUlO, E.; CARVALHO, L. N. G.; GIRÃO, L. F. A. P. Algumas Questões Sobre a Normatização Contábil Baseada em Princípios, Regras e Objetivos. Revista Evidenciação Contábil \& Finanças, v. 2, n. 2, p. 24-39, mai./ago. 2014. Disponível em: http://periodicos.ufpb.br/index.php/recfin/article/view/20181/11312. Acesso em: 10 ago. 2017.

PELEIAS, I. R. et al. Interdisciplinaridade no ensino superior: análise da percepção de professores de controladoria em cursos de ciências contábeis na cidade de São Paulo. Avaliação, v. 16, n. 3, p. 499-532, 2011. Disponível em: http://www.scielo.br/pdf/aval/v16n3/v16n1a02.pdf. Acesso em: 14 set. 2017.

PRATT, Michael G. For the Lack of a Boilerplate: Tipson Writing Up (and Reviewing) Qualitative Research. Academy of Management Journal v. 52, n. 5, p. 856-862, 2009. https://doi.org/10.5465/amj.2009.44632557

SÁ, A. L. Teoria da contabilidade. 4. ed. São Paulo: Atlas, 2006.

SÁ, A. L. Consultoria e análise contábil. Curitiba: Juruá, 2012.

SILVA, I. M. M. Pronunciamentos técnicos do CPC: um estudo sobre a influência da subjetividade na informação contábil. In: Congresso ANPCONT, 5, 2011, Vitória.

Anais...ANPCONT, 2011.

SILVA, M. P. Elementos aplicados à contabilidade: em busca de um sistema filosófico contábil. 2014. 170 f. Dissertação (Mestrado em Controladoria e Contabilidade) - FECAP Faculdade Escola de Comércio Álvares Penteado, São Paulo, 2014.

SMITH, G. F. Beyond Thinking and Decision Making: Teaching Business Students How to Think. Journal of Management Education, v.27, n1, p.24-51. 2003.

https://doi.org/10.1177/1052562902239247

SPRINGER, C. W.; Borthick, F. Improving performance in accounting: Evidence for insisting on cognitive conflicts. Issues in Accounting Education. 2007.

https://doi.org/10.2308/iace.2007.22.1.1

SZÜSTER, N.; SZÜSTER, F. R.; SZÜSTER, F. R. Contabilidade: Atuais Desafios e Alternativa Para Seu Melhor Desempenho. Revista de Contabilidade \& Finanças da USP. São Paulo, n. 38, p. 20 - 30, Mai./Ago. 2005. Disponível em:

http://www.revistas.usp.br/rcf/article/view/34156/36888. Acesso em: 05 jul. 2017.

TRIVIÑOS, A. N. S. Introdução à pesquisa em ciências sociais a pesquisa qualitativa em educação. São Paulo: Atlas, 1987.

TROMBETTA, D.; TROMBETTA, L. C. A filosofia e a sociologia aplicadas às Ciências Contábeis. Revista Eletrônica do Curso de Ciências Contábeis, n. 7, p. 100-126, 2015. 
Disponível em: https://seer.faccat.br/index.php/contabeis/article/view/297. Acesso em: 22 ago. 2017.

VIEIRA, S. E.; CASTANHO, M. E. A disciplina de filosofia nos cursos superiores de administração: uma análise institucional. Revista Aprender. v.1, n 12, 2009. Disponível em: http://periodicos2.uesb.br/index.php/aprender/article/view/3110. Acesso em: 18 jul. 2017.

WEFFORT, E. F. J. O Brasil e a harmonização contábil internacional: influências dos sistemas jurídico e educacional, da cultura e do mercado. São Paulo: Atlas, 2005.

Uma versão preprint do artigo foi apresentada do Congresso de Administração, Sociedade e Inovação (CASI), 2017. 